The Thinking Computer: Mind Inside Matter. By Bertram Raphael. Pp. xiii+ 322. (Freeman: San Francisco and Reading, May 1976.) Cloth £9; paper $£ 4.40$.

Artificial InTElligence (AI) is beset by all the difficulties of any immature science. Since so little is agreed among its workers in the way of basic theory and truths, any presentation of it is bound to be inadequate, and that applies especially to any attempt to produce a non-contentious introductory text like the one under review. It is almost inevitable that such a work will be parochial in terms of the research laboratory it comes from, and the areas within the field on which it concentrates. To say this is not to blame the author: in the present state of things in AI it could not be otherwise.

Thus the present book is heavily oriented to the research carried out at the Stanford Research Institute (SRI), its author's home, and is strongest in the areas where SRI is strong: robots, formal approaches to problem solving and vision; and weakest where they are weakest: natural language, high level programming languages, and the sort of speculation about 'knowledge structures' that has been emerging from MIT in the past two years. The book seems to have been written essentially by about 1972, and is, in that sense, out of date. But, once again, it is a criticism of the subject and not the author that being up to date is considered so important in AI. In a mature science, the basics could be absorbed perfectly well from a four-year-old textbook. In so far as abstract problemsolving techniques, resolution theory in theorem proving, and techniques of the same vintage in vision, are fundamental building blocks of the subject (and to some extent it is undeniable that they are), then they are well and clearly presented here.

The book aims to fill the gap between a wholly popular account of AI research and the style of the technical literature; and is intended to lead anyone interested and armed with 'High School' maths to that literature. It does it rather well, and could be a useful book for first-year University courses in computer science or psychology.

Its concessions to laymen are among its best bits. Raphael begins by tackling what he calls "myths about computers": the Arithmetic Myth and the Stup:d Computer Myth, namely that computers can do only what they are programmed to do, which is true but highly misleading. While he was at it he should probably have tackled the contrary myths: that computers are socially all-powerful and as clever as we are. The latter is just as likely to be believed by the man in the street at the moment as the "myths" Raphael does tackle. The book's subtitle, too, Mind Inside Matter, is peculiarly unfortunate for an author concerned to debunk myths.
Another bonus is the well illustrated chapter on the history of robots, which contains the marvellous revelation ( $p$ 253) that "several key figures in contemporary computer history"-Von Neumann, Wiener and Minsky-are all descendants of the Maharal: the fifteenth-century rabbi of Prague who made, and gave life to, a 'golem', an antificial man made from the clay of a river bank.

Yorick Wilks has worked on Artificial Intelligence and natural language understanding at Cambridge, Stanford and in Switzerland. He is at present a Senior Visiting Fellow at the University of Edinburgh, UK.

\title{
Matrix isolation
}

Matrix Isolation: A Technique for the Study of Reactive Inorganic Species. By Stephen Cradock and A. J. Hinchcliffe. Pp. 144. (Cambridge University : Cambridge, London and New York, October 1975.) $£ 6.20$.

Now acknowledged as one of the primary methods of investigating molecules which are short-lived in conventional conditions, matrix isolation has not lacked reviewers, but books about it have been few and relatively specialised. The present authors are to be commended therefore on producing a compact and eminently readable account of matrix isolation which can easily be digested by undergraduate and graduate students unfamiliar with the technique. The formation and nature of a matrix, interactions within that matrix, and the technical aspects of matrix-isolation experiments are treated at a simple, descriptive level; specific examples are discussed in the closing chapters. There is a short subject index and a cameo-sized bibliography that is bound to disappoint anyone with more than passing interest in the subject.

Assuming that the reader is familiar with much basic physics, chemistry and spectroscopy, the authors have aimed to show how matrix-isolation experi- ments may be accomplished. Assuredly, theirs is a reasonable objective, but the result seems to me overburdened with empiricism, and addicted to assertions unsupported either by argument or by apt example. Without a broader appreciation of the purpose and possibilities of the technique, the reader might be excused for wondering whether the technical mountain has not given birth to a chemical mouse. This doubt is not altogether dispelied either by the range or by the treatment of the examples selected. Certain it is that the authors take a healthily critical view of the results of matrix-isolation experiments: whether those results signify much outside their immediate context has to be taken on trust. If the figures would have repaid a greater expenditure of imagination and trouble, the way in which the story is told recalls Mark Twain's character: "there was things which he stretched, but mainly he told the truth". Mainly this is a sound and worthwhile addition to the chemical literature: it might have been more than that.

\section{A. J. Downs}

Dr Downs is a Lecturer in the Department of Inorganic Chemistry at the University of Oxford, UK. 